\title{
Local delivery of AAV2-CTLA4lgG decreases sialadenitis and improves gland function in the C57BL/6.NOD-Aec1Aec2 mouse model of Sjögren's syndrome
}

Hongen Yin ${ }^{1 \dagger}$, Cuong Q Nguyen ${ }^{2 \dagger}$, Yuval Samuni ${ }^{1}$, Toshimitsu Uede ${ }^{3}$, Ammon B Peck ${ }^{2}$ and John A Chiorini ${ }^{1 *}$

\begin{abstract}
Introduction: Cytotoxic T-lymphocyte antigen 4 (CTLA-4) is a key negative costimulatory molecule that displays a wide range of anti-inflammatory properties and is currently approved to treat rheumatoid arthritis as a recombinant fusion protein (CTLA4lgG). To better understand the role of CTLA4lgG in primary Sjögren's syndrome (pSS), we generated a recombinant adeno-associated virus vector serotype 2 (AAV2) expressing a chimera of mouse CTLA-4 fused with a human immunoglobulin (AAV2-CTLA4lgG) and observed the effect of this molecule in C57BL/6.NOD-Aec1Aec2 mice, an animal model of pSS.

Methods: A recombinant adeno-associated virus-2 (AAV-2) vector was constructed encoding a CTLA4lgG fusion protein. The AAV2-CTLA4IgG vector and an AAV2 control vector encoding beta galactosidase (LacZ) were administered by retrograde cannulation of the submandibular glands of C57BL/6.NOD-Aec1Aec2 mice. Protein expression was measured by ELISA and salivary glands were assessed for inflammation and activity.

Results: Recombinant CTLA4lgG blocked B7 expression on macrophages in vitro. In vivo, localized expression of CTLA4lgG in the salivary glands of C57BL/6.NOD-Aec1Aec2 mice inhibited the loss of salivary gland activity and decreased T and B cell infiltration as well as dendritic cells and macrophages in the glands compared with control mice. In addition a decrease in several proinflammatory cytokines and an increase in transforming growth factor beta-1 (TGF- $\beta$ 1) expression were also observed.

Conclusions: These data suggest expression of CTLA4lgG in the salivary gland can decrease the inflammation and improve the xerostomia reported in these mice.
\end{abstract}

Keywords: Sjögren's Syndrome, salivary gland dysfunction, adeno-associated virus (AAV), CTLA4lgG fusion protein, prevention

\section{Introduction}

Primary Sjögren's syndrome (pSS) is a chronic autoimmune disorder that results in impaired exocrine gland function. Xerostomia (dry mouth) and xerophthalmia (conjunctivitis sicca, dry eyes) are hallmarks of Sjögren's syndrome [1]. The mechanism associated with Sjögren's syndrome is unclear however, immunologically-activated

\footnotetext{
*Correspondence: jchiorini@dir.nidcr.nih.gov

+ Contributed equally

${ }^{1}$ Molecular Physiology and Therapeutics Branch, National Institute of Dental and Cranial Research, National Institutes of Health, 10 Center Drive,

MSC1190, Bethesda, MD 20892, USA

Full list of author information is available at the end of the article
}

or apoptotic glandular epithelial cells may present novel autoantigens in predisposed individuals driving autoimmune-mediated tissue injury $[2,3]$. Immune activation is typically presented as focal, mononuclear $(\mathrm{T}, \mathrm{B}$, dentritic, and macrophage) cell infiltrates, proximal to the ductal epithelial cells and forms sialadenitis [2]. Lymphocytic infiltrations in the salivary gland (SG) and lachrymal glands (LG) consist of $60 \%$ to $70 \%$ CD4+ Tlymphocytes, and a substantial numbers of B cells, dendritic cells (DCs), plasma, and macrophage $(M \phi)$ cells $[2,4,5]$. Abnormal activation of proinflammatory Th1 $[6,7]$, and Th17 [8] cells and cytokines such as

\section{C) Biomed Central}


interferon- $\gamma$ (IFN- $\gamma$ ), interleukin-12 (IL-12), IL-17 were reported in animal models of pSS and patient samples [7-11]. In addition, a dramatic drop in T regulatory cells (Treg) and decreased expression of TGF- $\beta 1$ in SG infiltrates was also reported in pSS patients [12]. Furthermore, TGF- $\beta 1$ deficient mice develop a Sjögren's syndrome like autoimmune disease [13].

Cytotoxic T-lymphocyte antigen 4 (CTLA-4) is an important immune regulatory protein and displays a wide range of activities associated with immune tolerance. By competing with CD28 to bind B7-1/2 (CD80/ CD86), CTLA4 blocks the activation of T cells, thus maintaining immune homeostasis [14]. CTLA-4 is constitutively expressed on Treg cells and also binds to B7 on antigen-presenting cells (APCs) to inhibit activation of effector T cells $[15,16]$. Recently it is noted that epithelial cells in the minor SGs of pSS patients express costimulatory molecules B7.1 (CD80) and B7.2 (CD86) [17]. Correspondingly, different haplotypes of CTLA-4 were found to be associated with increased susceptibility to pSS [18].

Currently, a recombinant fusion protein of CTLA4immunoglobulin (CTLA4-Ig, Abatacept, Orencia) is licensed in the United States for the treatment of rheumatoid arthritis [5]. Abatacept, which contains the CTLA-4 high-affinity binding site for B7 blocks B7: CD28 costimulatory signaling pathway and is reported to shut down activation of proinflammatory $\mathrm{T}$ cells [19] as well as B cells, DCs, and M $[20,21]$.

In order to study the affect of CTLA4 blockade on the sialadenitis and xerostomia associated with Sjögren's syndrome, CTLA4IgG was locally expressed in the salivary glands of C57BL/6.NOD-Aec1Aec2 mice, which develop a Sjögren's syndrome-like disease. Our findings of both functional and immunological improvement in the mice warrant further investigation of CTLA4 mediated immunomodulation as a therapeutic pathway for treatment of pSS patients.

\section{Materials and methods Cell lines}

HEK-293T cells were grown in Dulbecco's modified Eagle's medium (DMEM). Medium was supplemented with 10\% heat-inactivated fetal bovine serum (Life Technologies, Rockville, MD, USA), $2 \mathrm{mM}$ L-glutamine, penicillin $(100 \mathrm{U} / \mathrm{ml})$, and streptomycin $(100 \mu \mathrm{g} / \mathrm{ml}$; Biofluids, Rockville, MD, USA) as previously described [22].

\section{Construction and testing of AAV2-CTLA4IgG}

We previously reported construction of AAV2-LacZ [23]. In this study we used the extracellular domain of mouse Cytotoxic T-lymphocyte antigen 4 (CTLA4) coupled to human Immunoglobulin G (IgG) $\mathrm{C} \gamma 1$ (CTLA4IgG), kindly provided by Dr Toshimitsu Uede
(Institute of Immunological Science, Hokkaido University, Hokkaido, Japan) [24]. This gene was cloned into the recombinant adeno-associated virus (AAV) plasmid containing a cytomegalovirus (CMV) promoter and the inverted terminal repeat (ITRs) sequences for AAV serotype 2 (AAV2). The plasmid (AAV2-CTLA4IgG) was transfected into HEK-293T cells and expression of the protein in the media was determined by western blotting after electrophoresis in reducing conditions using anti-mCTLA4 Ab (R\&D systems, Minneapolis, MN, USA).

\section{Competitive inhibition of B7 association by CTLA4IgG in vitro}

Mouse macrophages (CRL-2751, ATCC) were grown in DMEM with $4 \mathrm{mM}$ L-glutamine, $1.5 \mathrm{~g} / \mathrm{L}$ sodium bicarbonate, $4.5 \mathrm{~g} / \mathrm{L}$ glucose (Biofluids, Rockville, MD, USA), $10 \%$ fetal bovine serum, and 20\% LADMAC conditioned media (produced from the LADMAC cell line (CRL$2420)$ at $37^{\circ} \mathrm{C}$ in a humidified, $5 \% \mathrm{CO}_{2}$ atmosphere, incubator. $1 \times 10^{5}$ cells/well were placed in round bottom 96-well plates and spun down at $1500 \mathrm{rpm}$ in a bench top centrifuge at $4^{\circ} \mathrm{C}$. The cells were then washed twice with PBS (pH 7.4, 0.05\% Tween 20) and incubated for $1 \mathrm{~h}$ at $37^{\circ} \mathrm{C}$ with either medium from control HEK293T cells or from HEK-293T cells transfected with AAV2-CTLA4IgG. Following additional washes, the cells were incubated in the dark with 0.5 to $1 \mu \mathrm{g} / \mathrm{ml}$ of Armenian hamster IgG FITC-conjugated anti B7-1 (Santa Cruz Biotechnology, Santa Cruz, CA, USA) in blocking solution (PBS, pH 7.4, 0.5\% BSA) at $4^{\circ} \mathrm{C}$ for 40 min. The cells were then washed and analyzed by flow cytometry assay.

\section{Vector production}

To generate AAV2 vectors, we used the adenoviral helper packaging plasmid pDG. Fifteen-cm plates of approximately $40 \%$ confluent HEK-293 T cells were cotransfected with either AAV-LacZ or AAV-CTLA4IgG according to standardized methods [25]. Clarified cell lysates were adjusted to a refractive index of 1.372 by addition of $\mathrm{CsCl}$, and centrifuged at 38,000 rpm for 65 $\mathrm{h}$ at $20^{\circ} \mathrm{C}$. Equilibrium density gradients were fractionated and fractions with a refractive index of 1.369 to 1.375 were collected. The particle titer was determined by Q-PCR and the vector was stored at $-80^{\circ} \mathrm{C}$. On the day of vector administration to C57BL/6.NOD-Aec1Aec2 mice, the vector was dialyzed for $3 \mathrm{~h}$ against saline.

\section{Animals}

Three female and ten male C57BL/6.NOD-Aec1Aec2 mice, aged six weeks, were bred and maintained at the animal facility of the Department of Pathology, University of Florida, as described previously [26]. Baseline 
saliva and tear flow was collected from mice when they were six weeks old. Gene therapy studies, as described herein, were approved by the University of Florida's IACUC and IBC.

\section{AAV2 vector administration}

Mice were randomly grouped and vectors were delivered into the submandibular glands by retrograde instillation as previously described [22] (AAV2-LaZ: 1 female, 5 males and AAV2-CTLA4IgG: 2 females, 5 males). As previously reported, the vector was well tolerated with no vector related inflammation $[22,27]$. Briefly, eight-week-old mice were mildly anesthesized with ketamine $(100 \mathrm{mg} / \mathrm{ml}, 1 \mathrm{ml} / \mathrm{kg}$ body weight; Fort Dodge Animal Health, Fort Dodge, IA, USA) and xylazine $(20 \mathrm{mg} / \mathrm{ml}, 0.7 \mathrm{ml} / \mathrm{kg}$ body weight; Phoenix Scientific, St Joseph, MO, USA) solution given by intramuscular injection (IM). Ten minutes after IM injection of atropine $(0.5 \mathrm{mg} / \mathrm{kg}$ BW; Sigma, St Louis, $\mathrm{MO}$, USA), mice were administered $50 \mu \mathrm{lAAV} 2$ vector into both submandibular glands by retrograde ductal instillation $\left(1 \times 10^{10}\right.$ particles/gland $)$ using a thin cannula.

\section{Detection of CTLA4IgG expression in salivary glands and serum from C57BL/6.NOD-Aec1Aec2 mice}

To confirm the stable expression of CTLA4IgG in vivo after local delivery in the SGs from C57BL/6.NODAec1Aec2 mice, homogenates of SGs were prepared as described previously [7]. Total protein in the supernatant was determined with $\mathrm{BCA}^{\mathrm{TM}}$ protein assay kit (Pierce, Rockford, IL, USA) according to the manufacturer's instructions. Blood was collected by cardiac puncture at the time of sacrificing and collected in microcentrifuge tubes. Serum was separated by centrifugation for $20 \mathrm{~min}$ at $2000 \mathrm{~g}$ and stored at $-80^{\circ} \mathrm{C}$.

CTLA4IgG was detected by sandwich ELISA. A 96well plate (Nunc, Rochester, NY, USA) was incubated overnight $(\mathrm{O} / \mathrm{N})$ with $0.4 \mu \mathrm{g} / \mathrm{ml}$ capture antibody, goat anti-mouse CTLA-4 Ab (R\&D, Minneapolis, MN, USA) in carbonate/bicarbonate buffer ( $\mathrm{pH} 9.5$ ). The next day, wells were blocked and incubated with 100 $\mu \mathrm{L}$ of appropriately diluted standard control $(0.0850$ $\mu \mathrm{g} / \mathrm{ml}$ rCTLA4, R\&D, Minneapolis, MN, USA) or serum, undiluted SG homogenates for $2 \mathrm{~h}$ according to the product instructions. Following three washings, the wells were incubated with a 1:5,000 dilution of peroxidase conjugated affinity purified goat antihuman IgG (Jackson ImmunoResearch, West Grove, PA, USA) for $1 \mathrm{~h}$ at RT. Substrate reaction was developed following the manufacturer's protocol and the plate were read at OD $450 \mathrm{~nm}$ using a Microplate reader model 680 (Bio-Rad Laboratories, Hercules, CA, USA) [7].

\section{Measurement of salivary and tear flow rates}

Pilocarpine stimulated saliva flow rate (SFR) and tear flow rate (TFR) collection was performed as described previously [8] at the indicated time points. Briefly, individual non-anesthetized mice were weighed and given an i.p. injection of $100 \mu \mathrm{l}$ of PBS containing a mixture of isoproterenol $(0.02 \mathrm{mg} / \mathrm{ml})$ and pilocarpine $(0.05 \mathrm{mg} /$ $\mathrm{ml})$. Saliva was collected from the oral cavity of individual mice for $10 \mathrm{~min}$. At week 30, tear volumes from individual animal were measured after i.p. injection of pilocarpine $(4.5 \mathrm{mg} / \mathrm{g}[\mathrm{BW}])$ for $20 \mathrm{~s}$ and determined using a phenol red thread (Zone-Quick, FCI Ophthalmics, Pembrooke, MA, USA), a modified version of the Schirmer test as described [8]. SFR and TFR were then calculated per gram body weight.

\section{Determination of autoantibodies}

At the end of the study, serum was collected from 30week-old C57BL/6.NOD-Aec1Aec2 mice. An ELISA was developed as described previously [7] to detect autoantibodies against SSA/Ro [multiple antigenic peptide (MAP)-Ro273] (University of Oklahoma Health Sciences Molecular Biology core Facility, Oklahoma City, OK, USA). Autoantibodies against SSB/La (total Ig) were measured by a commercially available ELISA kit (Alpha Diagnostic International, San Antonio, TX, USA) according to the manufacturer's protocol.

\section{Histological assessment of salivary glands}

Following euthanasia, whole SGs were surgically removed from each mouse and placed in $10 \%$ phosphate-buffered formalin for $24 \mathrm{~h}$ for hematoxylin and eosin (H\&E) staining as described previously [10]. Stained sections were observed under a microscope for glandular structure and leukocyte infiltration. Unstained sections were used for immunofluorescence and immunochemistry staining (below).

\section{Immunofluorescence staining for CD3+T cells and B220+B cells}

Immunofluorescence staining for $\mathrm{T}$ and $\mathrm{B}$ cells for the infiltrations in the SGs was done as previously described [8]. Briefly histological sections of salivary glands were incubated with rat anti-mouse B220 (BD Pharmingen, San Jose, CA, USA) and goat anti-mouse CD3 (Santa Cruz Biotechnology, Santa Cruz, CA, USA), followed by incubation with Texas Red-conjugated rabbit anti-rat IgG (Biomeda, Foster City, CA, USA) and FITC-conjugated rabbit anti-goat IgG (Sigma-Aldrich, St. Louis, MO, USA). The slides were mounted with DAPImounting medium (Vector Laboratories, Burlingame, CA, USA). Sections were observed at 200× magnification using a Zeiss Axiovert 200M microscope, and images were obtained with AxioVs40 software (Ver. 
4.7.1.0, Zeiss) (Carl Zeiss, Thornwood). The number of lymphocytic foci (LF) in each section was blindly enumerated by three individual investigators. The number of $\mathrm{B}$ and $\mathrm{T}$ cells, and total number of nuclei in each LF were determined using Mayachitra image software (Mayachitra, Inc., Santa Barbara, CA, USA).

\section{Immunohistochemical staining for CD11c and F4/80 in salivary glands}

Paraffin-embedded SGs were deparaffinized by immersion in xylene, followed by antigen retrieval with $10 \mathrm{mM}$ citrate buffer, $\mathrm{pH}$ 6.0. Tissue sections were then incubated overnight at $4^{\circ} \mathrm{C}$ with anti-CD11c or anti-F4/80 antibody (Santa Cruz Biotechnology Santa Cruz, CA, USA). Total rabbit IgG was used as an isotype control. The slides were incubated with biotinylated goat antirabbit IgG secondary antibody followed by horseradish peroxidase-conjugated strepavidin incubation using the Vectastain ABC kit. The staining was developed by using diaminobenzidine substrate (Vector Laboratories, Burlingame, CA, USA), and counterstaining was performed with hematoxylin. Sections were photographed at $200 \times$ magnification using a Zeiss Axiovert 200M microscope, and images were obtained with AxioVs40 software (Ver. 4.7.1.0, Zeiss) (Carl Zeiss, Thornwood). The number of CD11c or F4/80-positive cells was counted by three different examiners and the mean of three counting were determined.

\section{Detection of cytokines from immune cell cultures and SG homogenates}

Cytokines from spleen cell and draining lymph nodes (DLN) cell culture, serum, and homogenates of SGs were detected as described previously [28]. Briefly cells from spleen and submadibular salivary gland (SMGs) associated DLNs obtained from treated mice were isolated respectively and samples from mice in each group were pooled and cultured in 24-well plates at $5 \times 10^{6}$ cells/ml RPMI-1640 medium (Invitrogen, Carlsbad, CA, USA), containing HL-1 serum replacement (Cambrex Bioscience, Walkersville, MD, USA), with or without 1 $\mu \mathrm{g} / \mathrm{ml}$ Concanavalin A (ConA, Sigma-Aldrich, St Louis, MO, USA). Supernatants were collected after $48 \mathrm{~h}$ incubation. Serum and SMG homogenates were prepared as described previously $[7,28]$ and three samples from representative mice in each group were used for detection.

Murine interleukin-6 (IL-6), tumor necrosis factor- $\alpha$ (TNF- $\alpha$ ), IL-12 p70, interferon- $\gamma$ (IFN- $\gamma$ ), IL-18, IL-17, IL-23, transforming growth factor- $\beta 1$ (TGF- $\beta 1$ ), mast cell proteinase-1 (MCP-1), and macrophage inflammatory proteins-1 (MIP-1) were measured using a multiplex sandwich-ELISA assay (Aushon Biosystem Billerica, MA, USA). Duplicates for each sample were tested in three dilutions and the mean values of the duplicates from the optimal dilution were reported [28].

\section{Statistical analysis}

Mann-Whitney U test was used to analyze differences of cytokine production in serum. Unpaired student t-test was used to analyze differences between two experimental groups in other assays. All analyses were performed with GraphPad Prism statistical software (GraphPad Software Inc. version 4.02, La Jolla, CA, USA) using a $P$ value $\leq 0.05$ as statistically significant.

\section{Results}

Detection of CTLA4IgG and binding to B7 in vitro

Prior to analyzing stable expression of CTLA4IgG from AAV2-CTLA4IgG in the SGs of C57BL/6.NODAec1Aec2 mice, we confirmed both the expression and the biological activity of the fusion protein by western blot, and by blocking the B7:CD28 pathway in vitro, respectively.

Fusion of the $C \gamma 1$ domain of IgG to the binding domain of CTLA4 resulted in a chimeric protein of approximately $62 \mathrm{kDa}$. Secretion was confirmed by western blot of the cell culture media from transfected cells (Figure 1A).

Macrophages, like dendritic cells, are one of the antigen presenting cells (APCs) that express the costimulatory molecule B7. To test the ability of the recombinant CTLA4IgG to bind and block B7 detection, supernatant from CTLA4IgG expressing cells was preincubated with macrophages and then B7 quantified by flow cytometry assay. Compared to macrophages incubated without CTLA4IgG, unbound and detectable B7 expression on the macrophages incubated with CTLA4IgG was decreased, suggesting binding between B7 and CTLA4IgG.

\section{In vivo expression of CTLA4IgG following cannulation with AAV2-CTLA4lgG in C57BL/6.NOD-Aec1Aec2 mice} Salivary gland infiltrating lymphocytes in C57BL/6. NOD-Aec1Aec 2 are first detected between 8 and 12 weeks of age. However, microarray analysis indicates that adhesion molecules as well as genes associated with macrophages and dendritic cells are upregulation as early as 8 weeks of age. Prior to 8 weeks SGs are not considered fully mature. Thus, we chose to cannulate the glands at 8 weeks which would be considered an our early stage of disease [29]. As previously reported, cannulation of these mice with AAV vectors was well tolerated and no vector related inflammation was observed [22,27]. To confirm the stable expression of CTLA4IgG in vivo after local delivery of AAV2CTLA4IgG to the SGs of C57BL/6.NOD-Aec1Aec2 mice, SG homogenates and serum were obtained at the 


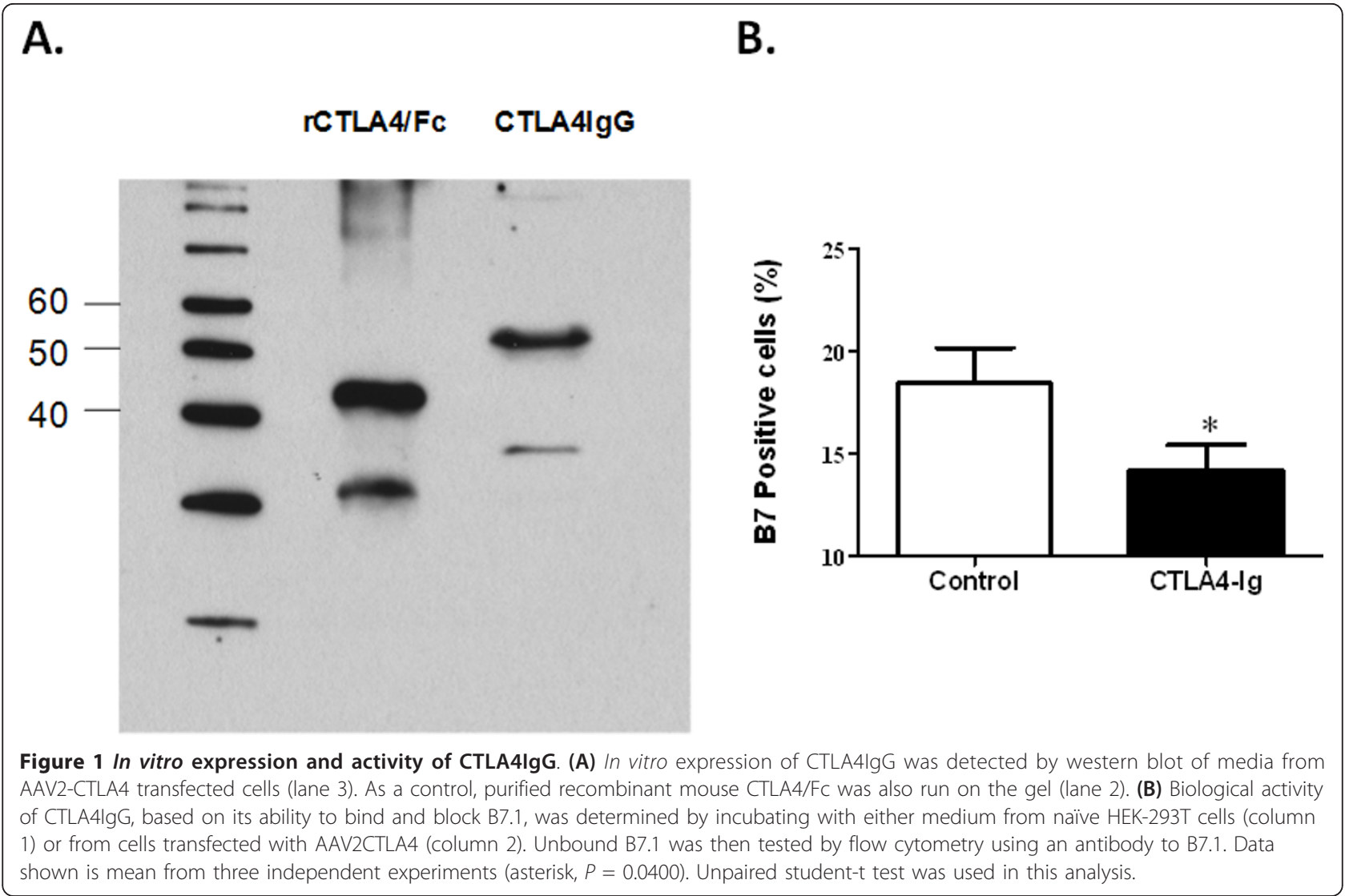

end of the study (30 weeks) and pooled according to each group. Using a sandwich-ELISA to detect the recombinant chimeric protein (mouse CTLA4 and human IgG), mice that received AAV2-CTLA4IgG had much higher levels of CTLA4IgG $(44.5 \pm 0.76 \mathrm{pg} / \mathrm{ml}$ in SG and $7.48 \pm 0.70 \mathrm{pg} / \mathrm{ml}$ in serum, mean $\pm \mathrm{SD}$ ) in both their SG and serum compared with mice that received vector expressing LacZ $(0.39 \pm 0.02 \mathrm{pg} / \mathrm{ml}$ in SG and $0.62 \pm 0.01 \mathrm{pg} / \mathrm{ml}$ in serum $)(P=0.0003$ and $P$ $=0.0102$, respectively, in SG and serum) (Figure 2). In agreement with the local delivery of vector, the level of expression in the SG homogenates was elevated compared with serum in the AAV2- CTLA4IgG-treated mice.

\section{Local expression of AAV2-CTLA4lgG prevents the age-} dependent loss of salivary gland activity in C57BL/6.NODAec1Aec2 mice

To better understand the effect of CTLA4IgG on SG function, stimulated saliva flow was measured in both treated and control mice over time. In agreement with previous studies [26], mice treated with the control LacZ expressing vector showed a significant decrease of saliva flow by 16 weeks $(4.25 \pm 0.64 \mu \mathrm{L} / \mathrm{g} 10 \mathrm{~min})$, compared with the baseline flow at 6 weeks $(6.10 \pm 0.30 \mu \mathrm{L} /$ g $10 \mathrm{~min}$ ), which continued to decline over time [8]. Mice that received AAV2CTLA4IgG vector initially also showed some decrease in saliva flow at 16 weeks $(5.13 \pm$ $1.22 \mu \mathrm{L} / \mathrm{g} 10 \mathrm{~min})$, but it was not statistically significant compared with the 6 -week baseline $(P=0.2057)$. However, by 22 weeks the saliva flow from the CTLA4IgG mice had recovered to near baseline values $(6.13 \pm 0.92$ $\mu \mathrm{L} / \mathrm{g} 10 \mathrm{~min}$ ), which was sustained for the remainder of the study, and was statistically different compared with the AAV2-LacZ-treated group at 30 weeks $(P=0.0222)$. These data suggest that expression of CTLA4IgG in the SGs of C57BL/6.NOD-Aec1Aec2 mice can inhibit the loss of SG function (Figure 3A).

\section{Salivary gland transduction with AAV2 CTLA4lgG had only minimal affect on lachrymal gland dysfunction in C57BL/6.NOD-Aec1Aec2 mice}

Previous research has suggested that following cannulation of the SG, greater than $90 \%$ of the AAV2 vector remains in the gland [27]. Similarly higher levels of the expression can also be detected locally in the gland homogenates compared with circulating levels. In order to test if the circulating levels of CTLA4IgG were sufficient to have an effect on other secretory epithelia such as the loss of lachrymal gland function in the C57BL/6. 


\section{A. CTLA4IgG expression in SGs}

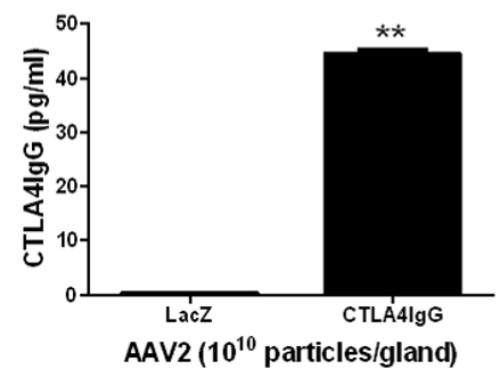

\section{B. CTLA4IgG expression in serum}

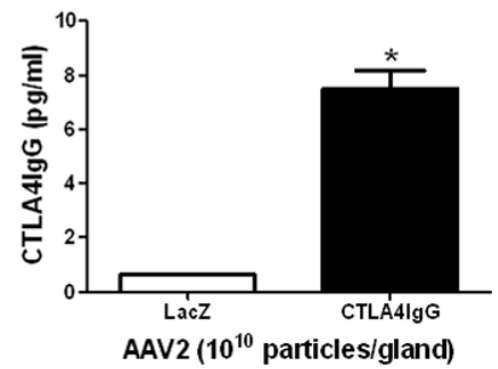

Figure 2 In vivo expression of CTLA4IgG in salivary glands from C57BL/6.NOD-Aec1Aec2 mice. A sandwich ELISA was developed to detect expression of mouse CTLA4 and human IgG (CTLA4IgG) chimeras in homogenates of submandibular salivary glands (A) and serum (B) (Materials \& Methods). Data show the mean \pm SEM from each group. Mice cannnulated with AAV2-CTLA4lgG ( $n=6$, pooled into two samples/group) had significant levels of CTLA4lgG protein in the salivary glands compared with mice that received AAV2-LacZ ( $n=7$, pooled into two samples/ group), (two asterisks, $P=0.0003$ ) and serum (asterisk, $P=0.0102$ ) Unpaired student-t test was used in this analysis.

NOD-Aec1Aec2 mice, we measured stimulated tear flow at the end of the study. CTLA4IgG-treated mice had an overall increase in tear flow compared with the LacZexpressing group, but was not significantly different $(P$ $=0.1316$ ) (Figure 3B).

\section{CTLA4IgG expression does not change autoantibody} levels in C57BL/6.NOD-Aec1Aec2 mice

To observe the effect of CTLA4IgG on the regulation of systemic B cell activation, we measured anti-Ro (SSA) and anti-La (SSB) autoantibodies, which are highly

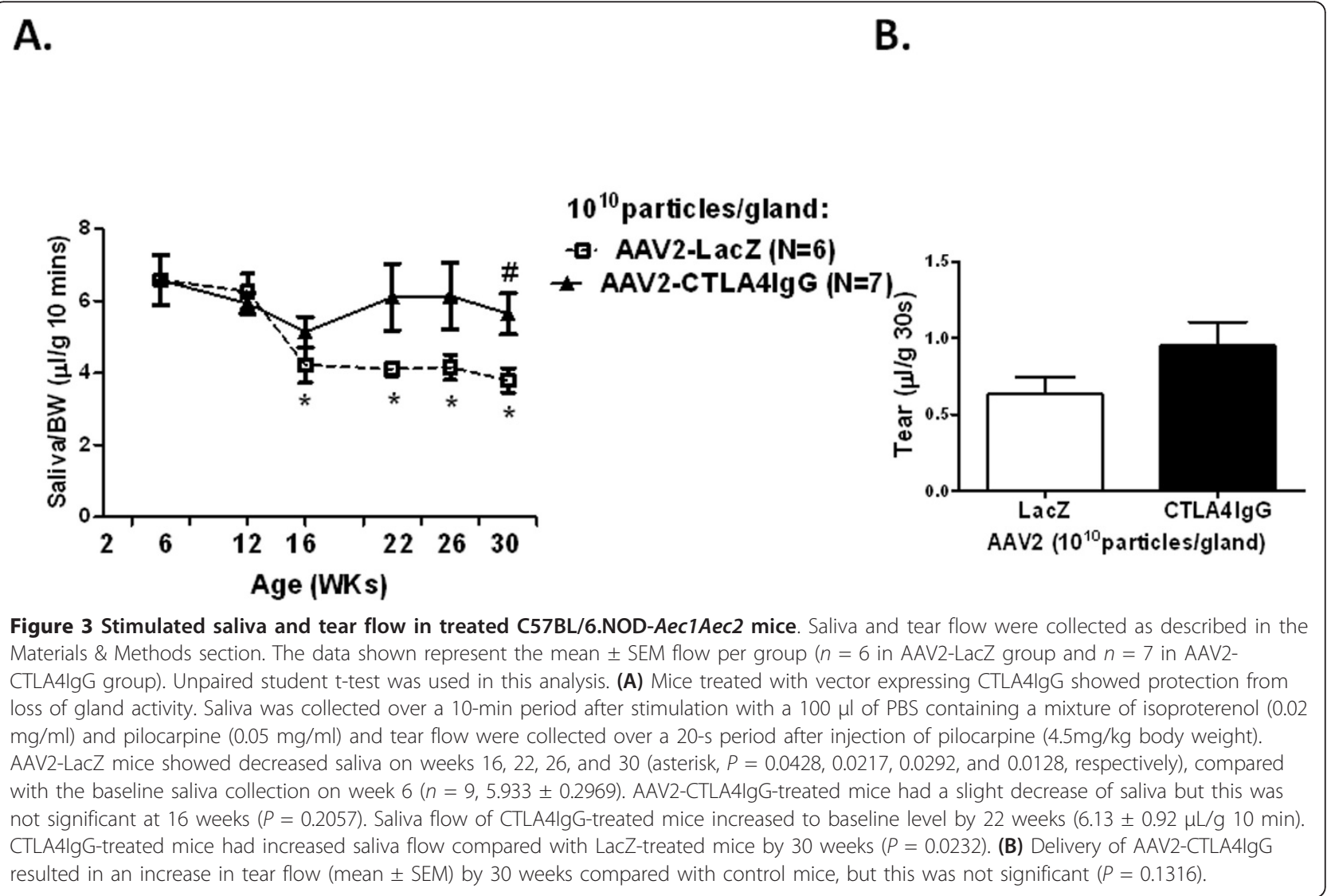


correlated with pSS [30]. Minimal changes in anti-Ro and anti-La titer were detected in the CLTA4IgG-treated mice compared with the AAV2-LacZ-treated mice (Figures $4 \mathrm{~A}$ and $4 \mathrm{~B}$ ).

\section{Salivary gland transduction with AAV2 CTLA4IgG can decrease infiltrating $T$ and $B$ cells, DCs, and $M \phi$}

To determine the effect of CTLA4IgG on lymphocyte foci (LF) in the SGs, we detected the number of LF as well as the number of $\mathrm{T}$ and $\mathrm{B}$ cells within the gland by immunofluorescence staining of CD3 and B220, respectively (Figures $5 \mathrm{~A}, \mathrm{~B}, \mathrm{C}$, and $5 \mathrm{D}$ ). The number of LF were decreased in the SGs of CTLA4IgG mice $(0.71$ LF/per gland) compared with control LacZ mice (2.16 LFs/per gland). Furthermore, the number of $\mathrm{T}$ and $\mathrm{B}$ cells present in the LF also decreased. Although the decrease in $\mathrm{T}$ cells was significant, the change in $\mathrm{B}$ cells was not statistically significant compared with control LacZ-treated mice $(P=0.0464$ and $P=0.3024$ for analysis of $\mathrm{T}$ and $\mathrm{B}$ cells, respectively) (Figures $5 \mathrm{C}$, $\mathrm{D}, \mathrm{E}$ and $5 \mathrm{~F}$ ).

An increase in DCs and macrophages has also been reported in the SGs of pSS patients [31]. The number of DCs and M cells (detected by staining for CD11c+ DCs and F4/80+, respectively) was significantly decreased in the CTLA4IgG-treated group compared with the LacZ control group (DCs: $13.33 \pm 2.78 /$ gland in LacZ group vs. $2.14 \pm 0.70 /$ per gland in CTLA4IgG mice, $P \leq 0.01$. Mф: $14.89 \pm 0.11 /$ gland in LacZ group vs. $3.84 \pm 2.31 /$ per gland in CTLA4IgG mice, $P$ $\leq 0.0001$ ) (Figure 5E, F, G, H, I, J, K and 5L). These data indicate that local expression of CTLA4IgG can inhibit T-cell accumulation in the SG, as well as DCs and $\mathrm{M \phi}$.
CTLA4IgG expression decreased proinflammtory cytokines and increased TGF- $\beta 1$ in salivary gland associated lymph nodes

To investigate cytokine production after CTLA4IgG expression, we measured the levels of cytokine associated with different populations of $\mathrm{T}$ cells or macrophages in both spleen and serum as well as locally in the SG and associated draining lymph nodes (DLN).

In SG homogenates, only a decrease in IL-6 was observed in the AAV2-CTLA4IgG-treated mice (median $=169.60 \mathrm{pg} / \mathrm{ml}$ ) compared with AAV2-LacZ controls $($ median $=86.51 \mathrm{pg} / \mathrm{ml})$, which was not statistically significant $(P=0.9062$, data not shown). Interestingly, TGF- $\beta 1$ production increased in the CTLA4IgG group compared with control LacZ-treated mice, however the increase was not statistically significant (median $=$ $1208.70 \mathrm{pg} / \mathrm{ml}$ vs. median $=804.53 \mathrm{pg} / \mathrm{ml}$, respectively) $(P=0.093$, data not shown). In the pooled cell culture media of the DLN cells associated with the SG, a general down-regulation in proinflammatory cytokine was observed in the CTLA-4IgG-treated mice compared with control LacZ mice. Th1 cytokines (IL-12, IFN- $\gamma$, and IL-18) and Th17 cytokine (IL-23) were all downregulated. Again, TGF- $\beta 1$ was strikingly up-regulated. In addition, non-specific proinflammatory cytokines, IL-6 and TNF- $\alpha$, as well as chemokines MCP-1 and MIP-1 $\alpha$, which are mainly released from macrophages, were decreased (Table 1). Little change was detected in Th2 cytokines such as IL-4, IL-5, and IL-13 after local expression of CTLA4IgG (data not shown). These changes suggest that CTLA4IgG expression can reduce proinflammatory cytokines released by Th1, Th17 cells, DCs, and macrophages, while stimulating production of anti-inflammatory cytokines such as TGF- $\beta 1$. This

\section{A. Serum anti-Ro/SSA}

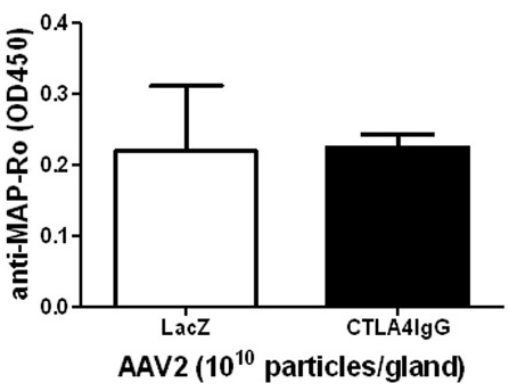

\section{B. Serum anti-La/SSB}

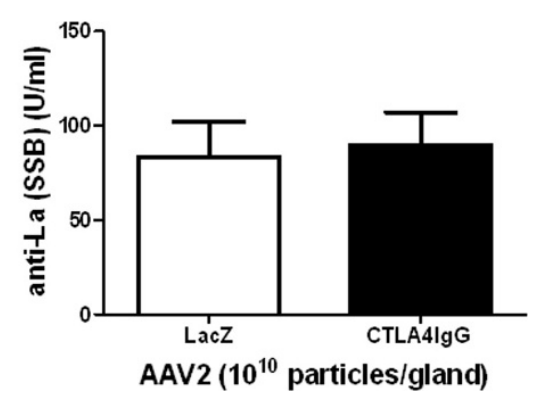

Figure 4 Serum anti-nuclear antibody productions in C57BL/6.NOD-Aec1Aec2 mice. Serum samples were analyzed for anti-Ro (SSA) (A) and anti-La (SSB) (B) antibody expression in serum from AAV2-LacZ $(n=6)$ and AAV2-CTLA4lgG $(n=7)$ treated mice by ELISA. The data shown represent the mean \pm SEM in OD or $\mathrm{U} / \mathrm{ml}$ from duplicate tests of pooled samples from each group. Unpaired student's t-test was used for statistical analysis. No statistically significant difference was detected ( $P=0.9586$ and 0.4158 , respectively). 


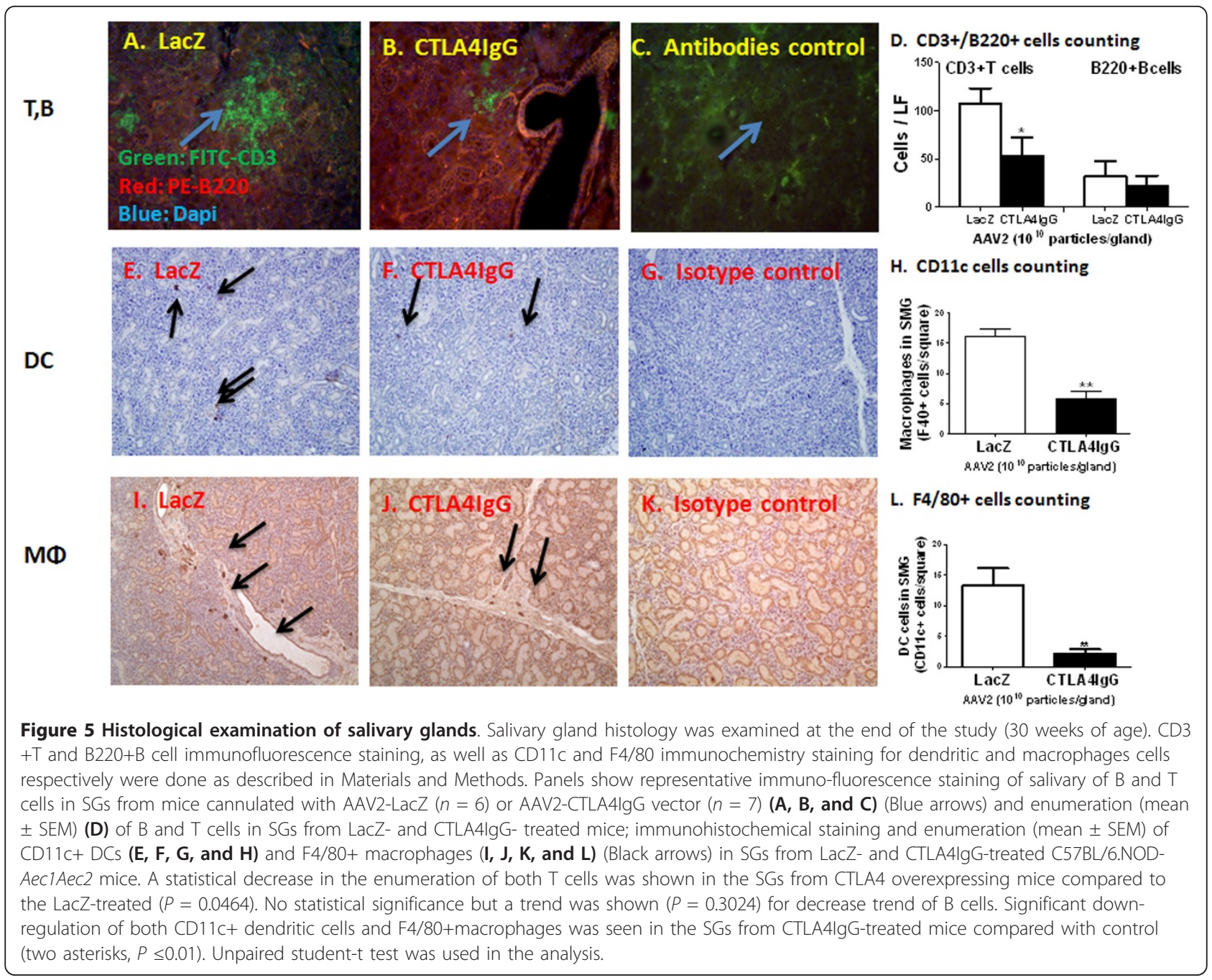

Table 1 Cytokine production local and systemic immune system in vector treated mice (pg/ml)

\begin{tabular}{llllllll}
\hline & & \multicolumn{2}{l}{ DLN cells } & \multicolumn{2}{l}{ Spleen cells } & Serum \\
\cline { 2 - 7 } & & LacZ & CTLA4IgG & LacZ & CTLA4IgG & LacZ & CTLA4IgG \\
\hline Th1- & IL-12p70 & 12 & $0.00 \downarrow$ & 4.6 & 0.20 & $88.5 \pm 15.8$ & $88.5 \pm 15.8$ \\
& IFN- $\gamma$ & 3.8 & $0.00 \downarrow$ & 122 & 115.0 & $872.6 \pm 1,276.8$ & $457.2 \pm 371.8 \downarrow$ \\
& IL-18 & 11 & $0.00 \downarrow$ & 16 & $0.00 \downarrow$ & $694 \pm 562$ & $394.10 \downarrow$ \\
Th17- & IL-17 & N/A & N/A & 2.1 & $0.00 \downarrow$ & $2.8 \pm 3.3$ & N/A $\downarrow$ \\
& IL-23 & 14 & N/A $\downarrow$ & 78.2 & $36.10 \downarrow$ & $335.6 \pm 365.7$ & $101.99 \downarrow$ \\
Treg- or SG epithelial cells & TGF- $\beta$ 1 & N/A & $41,410 \uparrow$ & 2,084 & 1,384 & $1,501,176 \pm 277,249$ & $1,260,620 \pm 289,478$ \\
Non-specific (Macrophages) & IL-6 & 2452 & $1,688 \downarrow$ & 2,557 & 2,407 & $309 \pm 1,241$ & $289 \pm 355$ \\
& TNF- $\alpha$ & 43 & $27 \downarrow$ & 98 & 120 & $37 \pm 83$ & $41 \pm 142$ \\
Chemokines & MCP-1 & 10 & $2 \downarrow$ & 44 & 43 & $63 \pm 19$ & $66 \pm 26$ \\
& MIP-1 $\alpha$ & 224 & $130 \downarrow$ & 357 & 237 & $2 \pm 0.2$ & $2.5 \pm 2.5$ \\
\hline
\end{tabular}

Serum, splenocytes, and salivary gland DLNs were collected at the end of the study. Splenocytes and DLN cells were pooled according to vector treatment group. Culture supernatants were collected following incubation with or without ConA for $48 \mathrm{~h}$. Cultures and serum were then analyzed for levels of the indicated cytokines (in pg/ml) by multi-cytokine assay in duplicate. For cell cultures, values are the mean of duplicate tests of ConA treated cells subtracted from media alone. For serum, the data shown were the median \pm SD of each group of mice (AAV2-LacZ [ $n=6]$ and AAV2-CTLA4lgG [ $n=7]$, respectively]. MannWhitney $U$ test was used to analyze differences of cytokine production in serum. $\uparrow$ : Production of cytokines in the AAV2-CTLA4lgG group is $\geq 50 \%$ higher than in AAV2-LacZ group; $\downarrow$ : Production of cytokines in the AAV2-CTLA4lgG group is $\geq 50 \%$ lower than the AAV2-LacZ group. 
further supports the finding of reduced inflammation with CTLA4IgG treatment.

\section{Effect of CTLA4IgG on regulation of systemic T cell response in the C57BL/6.NOD-Aec1Aec2 mice}

To test for changes in the systemic immune system, cytokines were also measured in serum and in spleen cell cultures. Wide variation was seen in cytokine values in serum, and none of the cytokine levels from the CTLA4IgG and LacZ groups showed statistical significance. However, a decrease (a change in the median of $\geq 50 \%$ ) in a majority of cytokines associated with Th1 and Th17 cells, such as IFN- $\gamma$, IL-18, IL-17, and IL-23, was seen in the serum of AAV2-CTLA4IgG-treated mice compared with AAV2-LacZ-treated mice. In addition, production of IL-12, IL-18, IL-17, and IL-23 from splenocytes was down-regulated in the AAV2CTLA4IgG-treated group compared with the AAV2LacZ-treated mice. Unlike the local immune response seen in the SG associated DLN, minimal change in nonspecific cytokines, chemokines, or TGF- $\beta 1$ was detected in serum or cultured splenocytes. These data imply that CTLA4IgG expression can also decrease proinflammatory cytokines in the peripheral immune system, following local SG gene transfer in C57BL/6.NOD-Aec1Aec2 mice (Table 1).

\section{Discussion}

The blockade of CD28 co-stimulation by recombinant CTLA4IgG (abatacept) has demonstrated clinical utility in the treatment of rheumatoid arthritis [14]. In our study, local expression of CTLA4IgG by gene transfer to the SGs of C57BL/6.NOD-Aec1Aec2 mice, a pSS animal model, resulted in a decrease in the sialoadenitis and improvement in gland function compared with mice that received a control vector.

The advantage of localized gene transfer is to direct the expression of the therapeutic molecule to the site of maximum effect while minimizing the systemic complications that can be associated with off target effects. Using this approach we were able to achieve much higher local concentrations of CTLA4IgG in the salivary glands compared to circulating levels in the serum. Our data further confirm that ductal cells within the gland represent a good depot site for production of recombinant proteins [32]. Indeed, previous experiments have demonstrated expression from salivary gland ductal cells for the life of the animal [33].

In both patients and C57BL/6.NOD-Aec1Aec2 mice, activated CD4+ T lymphocytes including Th1 and Th17 cells infiltrate the salivary and lachrymal glands, and produce a variety of proinflammatory cytokines, such as IFN- $\gamma$ and IL-17, which may trigger gland damage and represent a crucial element in the pathogenesis of pSS
$[2,34]$. Although not statistically significant, we did detect a decrease in Th17 cytokine in both the DLN and spleen following expression of CTLA4IgG, suggesting a corrective shift in this critical cell population.

Besides the negative effect on $\mathrm{T}$ cells as a result of blockade of the B7:CD28 costimulatory pathway [19], it is also noted that recombinant CTLA4IgG may directly or indirectly deactivate DCs, macrophages and B lymphocytes $[15,21]$. Our data indicate that in C57BL/6. NOD-Aec1Aec2 mice, CTLA4IgG expression results in a decrease in $\mathrm{T}$ and $\mathrm{B}$ lymphocytes as well as DCs and macrophages in the SG that is accompanied by a downregulation in proinflammatory cytokines. Our finding is in agreement with previous reports on the effect of CTLA4IgG in other autoimmue disease model $[20,21]$.

Interestingly, a significant increase in TGF- $\beta 1$ expression in both the SG and the DLNs was observed. The increase in TGF- $\beta 1$ expression maybe related to an increase in nTreg or negative regulation of epithelial cells by CTLA4IgG [15]. In addition to its role in the immune system, TGF- $\beta 1$ expression was found to be important in maintaining epithelial tight junctions, an important component in the fluid movement of SGs [35] and therefore may be directly related to the improvement in saliva flow.

Our study suggests an improvement of SG function, which could result from the inhibition of sialadenitis after local expression of CTLA4IgG. This suggests that local delivery of AAV2-CTLA4IgG is a promising treatment of pSS. In addition, some improvement in lachrymal gland was also observed. This difference is likely related to the lower circulating levels of CTLA4IgG in the serum compared with the levels in the salivary gland. Despite the positive results achieved in this study, the circulating levels of CTLA4IgG are well below those clinically used with abatacept (http://packageinserts.bms. com/pi/pi_orencia.pdf). Further increases in the dose of vector or the use of vectors with improved gene transfer activity in the salivary gland are likely to result in higher circulating levels and may have a more significant impact on extraglandular manifestations of Sjögren's syndrome.

Gene therapy is still considered an experimental procedure. However, to date more than 200 clinical trials have been conducted and recently many are showing promising results in treating hemophilia, cancer, immunodeficiencies, and blindness. An ongoing trial targeting the salivary glands is also reporting positive results suggesting that gene transfer to the salivary gland is possible [36]. In summary, our data suggest that inhibition of the costimulatory pathway CD28 by expression of CTLA4IgG locally in the salivary gland can be a useful approach for reducing the inflammation and improving the secretory activity associated with Sjögren's syndrome. 


\section{Conclusions}

Our data suggest expression of CTLA4IgG can reduce the sialadenitis and improve secretory activity in a mouse model of pSS. In addition to identifying a novel intervention in pSS, our findings support the importance of co-stimulatory pathways as a therapeutic target of the disease.

\begin{abstract}
Abbreviations
AAV2: adeno-associated virus vector serotype 2; ANA: antinuclear antibodies; APC: antigen-presenting cell; CMV: cytomegalovirus; CTLA-4: Cytotoxic Tlymphocyte antigen 4; CTLA4-IgG: CTLA4-immunoglublin; DMEM: Dulbecco's modified Eagle's medium; IFN-ү: Interferon-;; IL: interleukin; IM: intramuscular injection; ITRs: inverted terminal repeat; LF: lymphocyte foci; LG: lachrymal glands; MAP: multiple antigenic peptide; MCP-1: mast cell proteinase-1; MIP1: macrophage inflammatory proteins-1; pSS: primary Sjögren's syndrome; SG: salivary gland; TGF- $\beta 1$ : transforming growth factor- $\beta 1$; TNF-a: tumor necrosis factor-alpha; Treg: T regulatory cells.
\end{abstract}

\section{Acknowledgements}

The authors thank Dr Gabor G Illei for critical review and helpful discussion of this manuscript.

\section{Author details}

${ }^{1}$ Molecular Physiology and Therapeutics Branch, National Institute of Dental and Cranial Research, National Institutes of Health, 10 Center Drive, MSC1190, Bethesda, MD 20892, USA. ²Department of Oral Biology, College of Dentistry, University of Florida, Gainesville, Florida. ${ }^{3}$ Section of Immunopathogenesis, Institute of Immunological Science, Hokkaido University, Sapporo, Hokkaido 060, Japan.

\section{Authors' contributions}

All authors were involved in drafting the article, revising it, and made important intellectual contributions. All authors approved the final version. Dr Chiorini had full access to all the data in the study and takes responsibility for the integrity of the data and accuracy of the data analysis. $H Y, C Q N, A B P$, and JAC were responsible for the study concept and design. $H Y, C Q N$, and YS were responsible for data acquisition. HY, CQN, YS, and JAC were responsible for the analysis and interpretation of the data.

\section{Competing interests}

This work was supported by an NIH NIDCR intramural research grant to JAC. None of the authors have a financial disclosure.

Received: 10 June 2011 Revised: 21 February 2012

Accepted: 27 February 2012 Published: 27 February 2012

\section{References}

1. Fox E, Khaliq AA, Sarwar M, Strickland GT: Chloroquine-resistant Plasmodium falciparum: now in Pakistani Punjab. Lancet 1985, 1:1432-1435

2. Voulgarelis M, Tzioufas AG: Pathogenetic mechanisms in the initiation and perpetuation of Sjogren's syndrome. Nat Rev Rheumatol 2010, 6:529-537.

3. Xanthou G, Tapinos NI, Polihronis M, Nezis IP, Margaritis LH, Moutsopoulos HM: CD4 cytotoxic and dendritic cells in the immunopathologic lesion of Sjogren's syndrome. Clin Exp Immunol 1999, 118:154-163.

4. Skopouli FN, Fox PC, Galanopoulou V, Atkinson JC, Jaffe ES, Moutsopoulos HM: T cell subpopulations in the labial minor salivary gland histopathologic lesion of Sjogren's syndrome. J Rheumatol 1991, 18:210-214.

5. Genovese MC, Becker JC, Schiff M, Luggen M, Sherrer Y, Kremer J, Birbara C, Box J, Natarajan K, Nuamah I, Li T, Aranda R, Hagerty DT, Dougados M: Abatacept for rheumatoid arthritis refractory to tumor necrosis factor alpha inhibition. N Engl J Med 2005, 353:1114-1123.
6. Bombardieri M, Barone F, Pittoni V, Alessandri C, Conigliaro P, Blades MC, Priori R, McInnes IB, Valesini G, Pitzalis C: Increased circulating levels and salivary gland expression of interleukin-18 in patients with Sjogren's syndrome: relationship with autoantibody production and lymphoid organization of the periductal inflammatory infiltrate. Arthritis Res Ther 2004, 6:R447-456.

7. Vosters JL, Landek-Salgado MA, Yin H, Swaim WD, Kimura H, Tak PP, Caturegli P, Chiorini JA: Interleukin-12 induces salivary gland dysfunction in transgenic mice, providing a new model of Sjogren's syndrome. Arthritis Rheum 2009, 60:3633-3641.

8. Nguyen $C Q, H u M H, L i$ Y, Stewart C, Peck AB: Salivary gland tissue expression of interleukin-23 and interleukin-17 in Sjogren's syndrome: findings in humans and mice. Arthritis Rheum 2008, 58:734-743.

9. Wu AJ, Chen ZJ, Baum BJ, Ambudkar IS: Interferon-gamma induces persistent depletion of internal $\mathrm{Ca} 2+$ stores in a human salivary gland cell line. Am J Physiol 1996, 270:C514-521.

10. Nguyen CQ, Yin H, Lee BH, Carcamo WC, Chiorini JA, Peck AB: Pathogenic effect of interleukin-17A in induction of Sjogren's syndrome-like disease using adenovirus-mediated gene transfer. Arthritis Res Ther 2010, 12:R220.

11. Leung S, Liu X, Fang L, Chen X, Guo T, Zhang J: The cytokine milieu in the interplay of pathogenic Th1/Th17 cells and regulatory $T$ cells in autoimmune disease. Cell Mol Immunol 2010, 7:182-189.

12. Li X, Li X, Qian L, Wang G, Zhang H, Wang X, Chen K, Zhai Z, Li Q, Wang Y, Harris DC: $T$ regulatory cells are markedly diminished in diseased salivary glands of patients with primary Sjogren's syndrome. I Rheum 2007, 34:2438-2445.

13. McCartney-Francis NL, Mizel DE, Redman RS, Frazier-Jessen M, Panek RB, Kulkarni AB, Ward JM, McCarthy JB, Wahl SM: Autoimmune Sjogren's-like lesions in salivary glands of TGF-beta1-deficient mice are inhibited by adhesion-blocking peptides. J Immunol 1996, 157:1306-1312.

14. Perkins D, Wang Z, Donovan C, He H, Mark D, Guan G, Wang Y, Walunas T, Bluestone J, Listman J, Finn PW: Regulation of CTLA-4 expression during T cell activation. J Immunol 1996, 156:4154-4159.

15. Takahashi T, Tagami T, Yamazaki S, Uede T, Shimizu J, Sakaguchi N, Mak TW, Sakaguchi S: Immunologic self-tolerance maintained by CD25(+)CD4(+) regulatory $T$ cells constitutively expressing cytotoxic $T$ lymphocyteassociated antigen 4. J Exp Med 2000, 192:303-310.

16. Sakaguchi $\mathrm{S}$, Ono M, Setoguchi R, Yagi H, Hori S, Fehervari Z, Shimizu J, Takahashi T, Nomura T: Foxp3+ CD25+ CD4+ natural regulatory T cells in dominant self-tolerance and autoimmune disease. Immunol Rev 2006, 212:8-27.

17. Matsumura R, Umemiya K, Goto T, Nakazawa T, Kagami M, Tomioka H, Tanabe E, Sugiyama T, Sueishi M: Glandular and extraglandular expression of costimulatory molecules in patients with Sjogren's syndrome. Ann Rheum Dis 2001, 60:473-482.

18. Downie-Doyle S, Bayat N, Rischmueller M, Lester S: Influence of CTLA4 haplotypes on susceptibility and some extraglandular manifestations in primary Sjogren's syndrome. Arthritis Rheum 2006, 54:2434-2440.

19. Moreland L, Bate G, Kirkpatrick P: Abatacept. Nat Rev Drug Discov 2006, 5:185-186.

20. Izawa A, Sano K, Takehara M, Inobe M, Suzuki J, Imamura H, Takahashi M, Ikeda U, Isobe M, Uede T: Cre/loxP-mediated CTLA4lgG gene transfer induces clinically relevant immunosuppression via on-off gene recombination in vivo. Cardiovasc Res 2006, 69:289-297.

21. Cutolo M, Soldano S, Montagna P, Sulli A, Seriolo B, Villaggio B, Triolo P, Clerico P, Felli L, Brizzolara R: CTLA4-Ig interacts with cultured synovial macrophages from rheumatoid arthritis patients and downregulates cytokine production. Arthritis Res Ther 2009, 11:R176.

22. Kok MR, Yamano S, Lodde BM, Wang J, Couwenhoven Rl, Yakar S, Voutetakis A, Leroith D, Schmidt M, Afione S, Pillemer SR, Tsutsui MT, Tak PP, Chiorini JA, Baum BJ: Local adeno-associated virus-mediated interleukin 10 gene transfer has disease-modifying effects in a murine model of Sjogren's syndrome. Hum Gene Ther 2003, 14:1605-1618.

23. Kaludov N, Brown KE, Walters RW, Zabner J, Chiorini JA: Adeno-associated virus serotype 4 (AAV4) and AAV5 both require sialic acid binding for hemagglutination and efficient transduction but differ in sialic acid linkage specificity. J Virol 2001, 75:6884-6893.

24. Kanaya K, Tsuchida Y, Inobe M, Murakami M, Hirose T, Kon S, Kawaguchi S, Wada T, Yamashita T, Ishii S, Uede T: Combined gene therapy with adenovirus vectors containing CTLA4lg and CD40lg prolongs survival of composite tissue allografts in rat model. Transplantation 2003, 75:275-281. 
25. Grimm D, Kern A, Rittner K, Kleinschmidt JA: Novel tools for production and purification of recombinant adenoassociated virus vectors. Hum Gene Ther 1998, 18:2745-2760.

26. Cha S, Nagashima H, Brown VB, Peck AB, Humphreys-Beher MG: Two NOD Idd-associated intervals contribute synergistically to the development of autoimmune exocrinopathy (Sjogren's syndrome) on a healthy murine background. Arthritis Rheum 2002, 46:1390-1398.

27. Katano H, Kok MR, Cotrim AP, Yamano S, Schmidt M, Afione S, Baum BJ, Chiorini JA: Enhanced transduction of mouse salivary glands with AAV5based vectors. Gene Ther 2006, 13:594-601.

28. Yin H, Vistica BP, Chan CC, Strominger JL, Gery I: Inhibition of experimental autoimmune uveitis by amino acid copolymers. I Neuroimmunol 2009, 215:43-48

29. Nguyen CQ, Sharma A, Lee BH, She JX, McIndoe RA, Peck AB: Differential gene expression in the salivary gland during development and onset of xerostomia in Sjogren's syndrome-like disease of the C57BL/6.NODAec1Aec2 mouse. Arthritis Res Ther 2009, 11:R56.

30. Whittingham S, Naselli G, McNeilage LJ, Coppel RL, Sturgess AD: Serological diagnosis of primary Sjogren's syndrome by means of human recombinant La (SS-B) as nuclear antigen. Lancet 1987, 2:1-3.

31. Greenspan JS, Daniels TE, Talal N, Sylvester RA: The histopathology of Sjogren's syndrome in labial salivary gland biopsies. Oral Surg Oral Med Oral Pathol 1974, 37:217-229.

32. Cotrim AP, Baum BJ: Gene therapy: some history, applications, problems, and prospects. Toxicol Pathol 2008, 36:97-103.

33. Voutetakis A, Kok MR, Zheng C, Bossis I, Wang J, Cotrim AP, Marracino N, Goldsmith CM, Chiorini JA, Loh YP, Nieman LK, Baum BJ: Reengineered salivary glands are stable endogenous bioreactors for systemic gene therapeutics. Proc Natl Acad Sci USA 2004, 101:3053-3058.

34. Tsunawaki S, Nakamura S, Ohyama Y, Sasaki M, Ikebe-Hiroki A, Hiraki A, Kadena T, Kawamura E, Kumamaru W, Shinohara M, Shirasuna K: Possible function of salivary gland epithelial cells as nonprofessional antigenpresenting cells in the development of Sjogren's syndrome. J Rheumatol 2002, 29:1884-1896.

35. Howe KL, Reardon C, Wang A, Nazli A, McKay DM: Transforming growth factor-beta regulation of epithelial tight junction proteins enhances barrier function and blocks enterohemorrhagic Escherichia coli 0157:H7induced increased permeability. Am J Pathol 2005, 167:1587-1597.

36. Samuni Y, Baum BJ: Gene delivery in salivary glands: from the bench to the clinic. Biochim Biophys Acta 2011, 1812:1515-1521.

doi:10.1186/ar3753

Cite this article as: Yin et al:: Local delivery of AAV2-CTLA4IgG

decreases sialadenitis and improves gland function in the C57BL/6.

NOD-Aec1Aec2 mouse model of Sjögren's syndrome. Arthritis Research \&

Therapy 2012 14:R40.

\section{Submit your next manuscript to BioMed Central and take full advantage of:}

- Convenient online submission

- Thorough peer review

- No space constraints or color figure charges

- Immediate publication on acceptance

- Inclusion in PubMed, CAS, Scopus and Google Scholar

- Research which is freely available for redistribution

Submit your manuscript at www.biomedcentral.com/submit 